\title{
Negative Transfer of Mother Tongue in English
}

\author{
Yanan Zhao \\ Baoding University, Baoding, China \\ Email: zhaoyanan876@sina.com
}

How to cite this paper: Zhao, Y. N. (2019). Negative Transfer of Mother Tongue in English. Creative Education, 10, 940-946. https://doi.org/10.4236/ce.2019.105070

Received: April 16, 2019

Accepted: May 18, 2019

Published: May 21, 2019

Copyright $\odot 2019$ by author(s) and Scientific Research Publishing Inc. This work is licensed under the Creative Commons Attribution International License (CC BY 4.0).

http://creativecommons.org/licenses/by/4.0/

\begin{abstract}
Many studies have shown that language acquisition has an important impact on Second Language Acquisition. The transfer of mother tongue falls into two kinds: positive transfer and negative transfer; positive transfer occurs when the habits of the two languages are similar; otherwise its negative transfer. Contrastive analysis, error analysis and inter-language theory have all deal with the negative transfer of language, which makes people understand native language's negative transfer better and develops foreign language teaching. Chinese senior school students learn English on the basis of their Chinese. So they would be affected by their mother tongue and their knowledge. Based on that, the present writer wants to find out students' problems in their English study by analyzing the mistakes according to language transfer theories. Such a study is also advantageous to the improvement of English teaching methods.
\end{abstract}

\section{Keywords}

Negative Transfer, Second Language Acquisition, Mother Tongue

\section{Introduction}

We are all very familiar with the phenomenon that an Indian speaks English quite fluently but inevitably with an Indian accent. In China we can often hear such kind of sentence as "I am student". Both the two examples are the results of mother tongue transfer. Transfer is a general term describing the carryover of previous performance or knowledge to subsequent learning. Positive transfer occurs when the prior knowledge benefits the learning task, that is, when a previous item is correctly applied to present subject matter. Negative transfer occurs when the previous performance disrupts the performance on a second task. The latter can be referred to as interference, in that previously learned material interferes with subsequent material, that is, a previous item is incorrectly transferred or associated with an item to be learned. The transfer of mother tongue 
has become an indisputable fact when it comes to Language Learning. The majority of high school students are still in the early stages of learning English, there are many disadvantages such as the environment of English learning is poor, limited vocabulary, lack of knowledge and ability to use English, so is vulnerable to mother tongue. In the recent years many researchers have found that many students who are in low level of second language extremely depend on the mother tongue (Corder, 1983: pp. 195-209), which always leads to negative or positive transfer; to the middle level students the negative transfer is especially obvious. From their articles we can find they write English compositions according to the way of Chinese; these articles generally are expressed as monotonous sentence, simple sentence stuffing, words and phrases mistaking, the grammar and expression just as Chinese thinking. So the negative transfer of mother tongue is one of the important factors to the English level of the high school students. However, in the current English teaching, due to various reasons, a large number of teachers lack of full understanding and analysis for the errors of language transfer in students' English writing. In English teaching lack of targeted teaching methods, the teaching effect is obvious. A lot of high school students are beset by the negative transfer. Therefore the present writer believes that through the analysis of the impact of the negative transfer of students' writing to guide and improve middle school English teaching is essential and necessary.

In the language learning the mother tongue has a negative or positive effect to the target language; through analysis one can find out how negative transfer of mother tongue affect the learning of foreign language, and why negative transfer leads to errors in the process of language learning. Before explaining how the negative transfer of mother tongue affects the senior high school students' English writing, the literature review about language transfer should be presented.

\subsection{Language Transfer}

\subsubsection{Definition of Language Transfer}

Language transfer is also known as cross-language influence (Odlin, 1989: p. 134), it is a key factor to promote the formation of language learners' inter-language. The study of language transfer has been a hot topic for researchers and workers in second language acquisition, but due to the linguists' dispute in a long time; it is difficult to have a precise definition. Based on the decades years about the language transfer in second language acquisition, Odlin put forward a simple and precise definition for language transfer "Transfer is the impact has caused by the similarities and differences between the target language and any other language which has been acquired" (Lado, 1994: p. 125).

According to the definition of Odlin, transfer not only refers to the effect from the mother tongue as the traditional study, but also any languages that the learner has acquired to the target language. Otherwise Odlin absorbed the reasonable part in the definition of Linguistic Influence by Sharwood Smith and Kellerman, who raised that transfer not only includes the errors but only the 
promote function just as negative transfer and positive transfer. This article discusses negative transfer of mother tongue in senior high students' writing and the significance to English teaching of the senior high school.

\subsubsection{Language Transfer Types}

The study of language transfer found that the similarity and difference among languages can lead to transfer of mother tongue, from the result of transfer it can be divided into two types: positive transfer and negative transfer.

Positive transfer refers to the similarity between the target language and mother tongue can promote the learning of second language, accelerating the development sequence of certain inter-language. It can help learner master some linguistic items for the second language. Positive transfer occurs when the learning task is same between the two languages, and permeates all parts of the language. Ellis pointed out that at the early stage of second language acquisition, facilitation of mother tongue is obvious, the reason is that at that time learners haven't constructed a developmental rule. Facilitation of the mother tongue depends on reducing the number of errors and learning speed. The same foundation of the language connection can help students accelerate learning pace.

Negative transfer refers to the interference of mother tongue, sometimes mother tongue cannot promote to learn a foreign language, to some extent even impede the learner to master some new language knowledge; this transfer is named negative transfer). Negative transfer occurs when the learning task of the two languages is relative but different, the learner of foreign language use the expression and understanding way of mother tongue to replace the way of foreign language. The reason is that the form and the regular system of the mother tongue and the target language are different but are regarded as same by the learner. The interference of mother tongue is common in the second language acquisition, negative transfer occurs in many ways of language.

\subsection{Relative Theory of Language Transfer}

\subsubsection{Contrastive Analysis Theory}

Language transfer application in Applied Linguistics is by comparing the native language and the target, so produce the Contrastive Analysis Theory (CAT). Contrastive analysis borrowed the two concepts in psychology, transfer and interference. The basic viewpoints are: the similar learning content of two languages leads to positive transfer; the different learning content of two languages lead to negative transfer; A third possibility is that a certain language feature in the target language is absent, which causes difficulties of second language learners. The target of the CA is that through comparing the difference between the learner's target language and mother tongue in pronunciation, vocabulary, grammar and analyzing the origin. On the one hand find the similarity to make the positive transfer be more successful, on the other hand, find the difference to reduce the interference.

Later the CAT caused many disputes, the main criticism of the theory in the 
two aspects: ability in the prediction error and theoretical basis. The reason why the CAT be suspected is that people expect too much of it, everyone hopes that it can predict all mistakes, which the learners made when they learn foreign languages, and become the only grounds of writing textbooks. CAT as a way to study language, although it's imperfection, it has been a very important way. A lot of studies have shown that transfer is a main type to learn new knowledge. The content, structure, condition of transfer can be learned by CAT. At present, the developmental tendency of foreign language teaching shows that there is a growing tendency to emphasize the development of communication and cross-cultural awareness. Maybe CAT is the best way to develop the two awareness.

\subsubsection{Inter-Language Theory}

Inter-language and is language acquisition theories based on cognitive psychology almost at the same time. Inter-language reflects two relative but different concepts. Firstly, it refers to the system of language structure which is constructed in the different stages of language development. Secondly it refers to a series of progressive system of language learners in the process of foreign language acquisition, namely inter-language continuum. The system is between the mother tongue and the target language, and it constantly changing with the increasing language input of learners. It is a dynamic system, has some characteristics such as systematic, openness, and incompleteness. It has some features such as: 1) Inter-language as a knowledge system of target language, which is constructed in the process of foreign language learning, it's different from mother tongue and target language. 2) As a continuum of knowledge, inter-language is evolving, and gradually closes to the target language. 3) As a process of foreign language learning, it's an inevitable phenomenon. In a conclusion, the study of Inter-language overcome the shortcomings of $\mathrm{CA}$ and $\mathrm{EA}$, absorb the reasonable part of them, make the content of second language acquisition be rich, it must promote the development of foreign language teaching.

\section{Analyses the Negative Transfer of Mother Tongue in English}

Vocabulary is the basic material of English writing, if the amount of vocabulary is insufficient, the writing is very difficult. Because of the vocabulary is insufficient, many students use mother tongue to replace the target language, the negative transfer of mother tongue occurs.

\subsection{Translation of Word-for-Word Convey the Wrong Meaning}

Many students translate according to the literal meaning in the writing; let every word correspondent between English and Chinese, which lead to mistakes. For example:

Washing clothes faces and brushing teeth shouldn't let water always running. 
Because using the washing machine needs much water.

Good good study, day day up.

And also in writing some students think that "kanbao" is explained in "look or see a newspaper", but "kanbao" in Chinese is "dubao" (read a book or newspaper). Because of the difference of the expression between Chinese and English, maybe one word in one language can be used to match a more extended filed in another language. For instance, "chi" is "eat", in English "eat" is used to modify food and fruit, but "chi" uses other ways in English. For example, "chiyao" is not "to eat medicine" but "to take medicine".

\subsection{Negative Transfer in Lexical Collocation}

Some words in English and Chinese, although the conceptual meaning and the connotative meaning are same, due to the different culture and habit, the collocation is different. For example:

The price of this dress is not expensive. (wrong)

The price of this dress is not high. (right)

The dress is not expensive. (right)

In Chinese "dafeng, dayu, daxue" but in English "big" cannot be collocated with "rain", "wind", "snowfall". It only can say "heavy rain" "strong wind" "heavy snowfall". In the communication, many learners use these phrases such as "learn knowledge", "build up one's mind", which are negative transfer in lexical collocation. The right expression should be "gain knowledge", "develop one's mind".

\subsection{Negative Transfer of Singular and Plural Forms}

There are no concepts of singular and plural in Chinese verb, and no suffix follow the none. But in English both of them exist, which makes Chinese students forget it. In the English writing it seems that the mistake is small, but it makes the composition incoherent and the quality reduced. For example:

It has many use. (wrong)

It has many uses. (right)

"Doing sports not only give our brain a chance to get relaxed but also reduce the possibility of getting ill" in this sentence the subject is "doing sports", so "give" and "reduce" should use "gives" and "reduces".

\section{How to Overcome Negative Transfer in English}

During the process of English writing, guiding students to understand the differences of Western culture in thought patterns between China and western countries through contrastive analysis. One should master the proper learning strategies, weaken negative transfer of mother tongue, according to the English habit of thinking to choose the words, sentences, and stylistic rules and improve the basic skills of writing to write authentic articles in English.

1) Establish correct attitude, so that students master scientific learning strategies 
Scientific approach of language transfer has great significance to solve the second language learning in translate issues. Cognitive psychology believes that learning is an active cognitive process, is the process of acquisition, conversion of new knowledge. For author of second language study, mother tongue constitutes most of the available information, and to the information stored in the brain of second language writers are scarce. Learning strategies is to be able to tolerate "Chinglish" to a certain extent. Students are encouraged to try to pay more for the target language, should not demanding perfection, and gradually reduce dependence on the mother tongue.

2) Emphasis on vocabulary and grammar teaching, so that students are familiar with the differences in English and Chinese vocabulary and syntax.

Expanding the amount of vocabulary, strengthen the students to grasp the meaning and usage of words correctly. Students should develop the capacity of collocations, use an appropriate expression according to the occasion, and improve accuracy and fluency of expression. Students can master some word-remembering skills, such as using word cards or use a notebook writing down the words that should remember and then take it so as to see the words as possible.

3) Strengthen the contrast between English and Chinese knowledge of teaching, and develop the awareness of cross-cultural.

In the teaching the thinking of English and Chinese should be contrasted, and develop the awareness of Intercultural communication. Teachers should guide students to compare the differences between the two ways of thinking in teaching, to understand its impact on the language, thereby enhancing cross-cultural awareness.

4) Increasing the language input of original authentic English, expanding the amount of reading, and setting real writing situation.

"The best way to enhance the knowledge of foreign languages is to live with the native people, and this after is a lot of reading". To get rid of Chinese interference, it requires a lot of reading, and develops English sense of students. While teaching the teachers should focus on teaching of discourse, through purposeful writing practice to enable students to understand the different characteristics of English and Chinese discourse.

\section{Conclusion}

The two languages have many differences in many aspects such as pronunciation, vocabulary, grammar, pragmatics, if not understanding these differences in second language acquisition, and just blindly applying the law and the mindset of the mother tongue, will inevitably result in negative transfer. Negative transfer of mother tongue is widely coverage in Second Language Acquisition and it also has a great influence in foreign language learning of second language learners. Although from some respects negative transfer of mother tongue is regarded as a communicative strategy, it helps learners overcome some problems in communication, which has positive function. The negative function to second language 
acquisition cannot be ignored either. Therefore one can by the contrastive way furthermore learn some background information of English countries from history, culture, and religion, and try to minimize the impact of cultural differences on Second Language Acquisition (Odln, 1994). And by reading the original and authentic expression of the sentence, develop the habit of thinking in English. Meanwhile, during the learning process of vocabulary, it is vital not only to clarify its concept meaning but also to understand the significance of culture and connotation.

\section{Conflicts of Interest}

The author declares no conflicts of interest regarding the publication of this paper.

\section{References}

Corder, S. P. (1983). A Role for the Mother Tongue. In S. Grass, \& L. Selinker (Eds.), Language Transfer in Language Learning.

Lado, R. (1994). Language Teaching a Scientific Approach. New York: McGraw-Hill.

Odlin, T. (1989). Language Transfer. Cambridge: Cambridge University Press. https://doi.org/10.1017/CBO9781139524537

Odln T. (1994). Language Transfer. Cambridge: Cambridge University Press. 